\title{
PURWARUPA GAME EDUKASI PENGENALAN WARNA BERBASIS ANDROID
}

\author{
Rizkysari Meimaharani $^{1)}$, Tri Listyorini ${ }^{2)}$ \\ ${ }^{1,2)}$ Prodi Teknik Informatika, Fakultas Teknik \\ Universitas Muria Kudus \\ e-mail: rizkyumk12@ gmail.com ${ }^{1)}$ trilistyorini@umk.ac.id ${ }^{2)}$,
}

\begin{abstract}
Abstrak
Perkembangan game dan android saat ini sangat pesat dan telah menjadi bagian bagian dari gaya hidup. Pembelajaran pengenalan warna sangat ditanamkan pada pendidikan anak usia dini. Hal ini dilakukan untuk melatih tingkat kreatifitas anak. Untuk menyampaian secara mudah dan menarik diperlukan media pembelajaran yang menarik dan interaktif. Penelitian ini menggunakan metode research and Development. Hasil dari penelitian ini adalah sebuah Game Edukasi ini dibuat untuk membantu guru untuk lebih meningkatkan minat anak terhadap pembelajaran pengenalan warna.
\end{abstract}

Kata Kunci: edukasi, warna, android, game, purwarupa.

\begin{abstract}
Game development and android is now very rapidly and have become part of the lifestyle section. Learning the introduction of color are very invested in early childhood education. This is done to train children's creativity level. For easy and attractive communication of necessary media learning engaging and interactive. This study uses research and Development. Results from this study is a game Education is designed to help teachers to further increase the interest of children to study the introduction of color.
\end{abstract}

Kata Kunci: education, color, android, game, prototype

\section{PENDAHULUAN}

Teori Permainan (Game) mula-mula dikemukakan oleh seorang ahli matematika Perancis Emile Borel (1921). Kemudian dikembangkan oleh John V,N dan Oscar Mogenstern lebih lanjut sebagai alat untuk merumuskan perilaku ekonomi bersaing yang berisi "Permainan terdiri atas sekumpulan peraturan yang membangun situasi bersaing dari dua sampai beberapa orang atau kelompok dengan memilih strategi yang dibangun untuk memaksimalkan kemenangan sendiri atau pun untuk meminimalkan kemenangan lawan. Peraturan-peraturan menentukan kemungkinan tindakan untuk setiap pemain, sejumlah keterangan diterima setiap pemain sebagai kemajuan bermain, dan sejumlah kemenangan atau kekalahan dalam berbagai situasi”. Sedangkan suatu metodologi yang berguna untuk melaksanakan percobaan dengan menggunakan model dari satu sistem nyata disebut dengan simulasi. Jadi simulasi adalah suatu teknik yang dapat digunakan untuk memformulasikan dan memecahkan model - model dari golongan yang luas. Golongan atau kelas ini sangat luasnya sehingga dapat dikatakan, " Jika semua cara yang lain gagal, cobalah simulasi”. Dari teori game dan simulasi ada keterkaitan antara keduanya, yaitu dengan adanya management simulation dan training simulation yang tak lain adalah jenis dari game simulais itu sendiri.

Perkembangan teknologi sekarang ini sudah beralih ke dalam sistem operasi android seiring dengan perkembangan hardware. Bahkan anak-anak telah mengenal smartphone yang berbasis android. Android merupakan sistem operasi yang open source dan dapat dikembangkan oleh peneliti-peneliti yang berkompeten di dalamnya.

Pada penelitian ini, peneliti mengusung tema game edukasi pengenalan warna berbasis android. Pembelajaran mengenai warna di TK Muslimat Khoiriyah Kudus masih pembelajaran yang konvensional. Dengan aplikasi ini diharapkan pembelajaran ini menjadi lebih menarik dan menarik. Luaran dari penelitian ini adalah sebuah game edukasi berbasis android dan jurnal nasional ber ISSN. 


\section{RUMUSAN MASALAH}

Rumusan masalah dalam penelitian Game Edukasi Pengenalan Warna berbasis Android yaitu Pembelajaran pengenalan warna di TK Muslimat Khoiriyah Kudus masih menggunakan cara konvensional dan belum adanya pembelajaran interaktif yang berbasis android.

\section{TUJUAN PENELITIAN}

Tujuan penelitian dalam penelitian Game Edukasi Pengenalan Warna berbasis Android antara lain Mengenalkan siswa mengenai pengenalan warna yang telah dikemas dalam Game Edukasi yang berbasis android, Meningkatkan cara belajar di TK Muslimat Khoiriyah Kudus yang sebelumnya konvensional menjadi berbasis multimedia.

Manfaat penelitian dalam penelitian Game Edukasi Pengenalan Warna berbasis Android antara lain Aplikasi Game Edukasi ini dapat menambah literatur dalam pembelajaran di TK Muslimat Khoiriyah Kudus, Meningkatkan kemampuan Universitas Muria Kudus dalam penelitian, pengembangan dan penerapan IPTEKS, dan Menjalin kerjasama antara Universitas Muria Kudus dengan TK Muslimat Khoiriyah Kudus.

\section{TINJAUAN PUSTAKA}

Metode dalam penelitian ini menggunakan metode propotype. Prototype Model adalah salah satu metode pengembangan perangkat lunak yang banyak digunakan. Dengan Metode Prototyping ini pengembangan dan pelanggan dapat saling berinteraksi selama proses pembuatan sistem. Sering terjadi seorang pelanggan hanya mendefinisikan secara umum apa yang dibutuhkan, Pemrosesan dan data-data apa saja yang dibutuhkan. Sebaliknya disisi pengembang Kurang memperhatikan efesiensi Algoritma. Kemampuan sistem oprasi dan interface yang menghubungkan manusia dengan computer (Pressman, 2007).

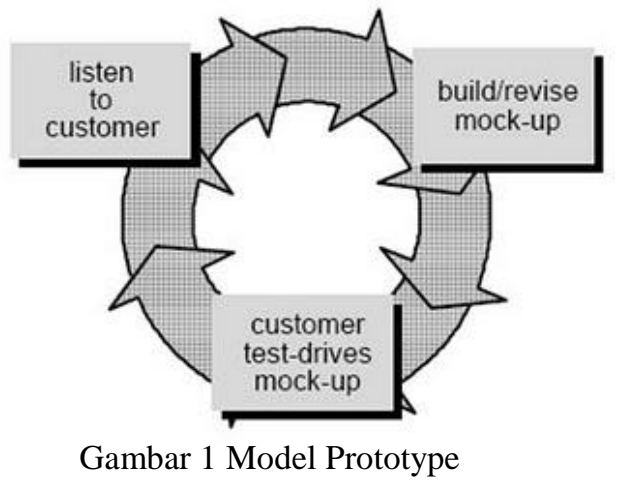

1. Tahapan Metodologi Prototipe :

Pengumpulan Kebutuhan dan perbaikan

Menetapkan segala kebutuhan untuk pembangunan perangkat lunak. Selain itu metode pengumpulan data dan wawancara juga dilakukan pada tahapan ini.

a) Observasi

Observasi atau pengamatan merupakan salah satu teknik pengumpulan data/fakta yang cukup efektif untuk mempelajari suatu sistem. Observasi adalah pengamatan langsung para pembuat keputusan berikut lingkungan fisiknya dan atau pengamatan langsung suatu kegiatan yang sedang berjalan. Dalam penelitian kali ini observasi dilakukan pada TK yang menjadi studi kasus dalam penelitian ini.

b) Wawancara

Dalam penelitian kali ini juga melakukan wawancara terhadap guru di TK yang menjadi tempat observasi peneliti. Hal ini dilakukan agar peneliti lebih mengetahui kebutuhan dari TK tersebut.

2. Desain

Tahap penerjemahan dari keperluan atau data yang telah dianalisis ke dalam bentuk yang mudah dimengerti oleh user.

3. Bentuk Prototipe

Menerjemahkan data yang telah dirancang ke dalam bahasa pemrograman.

4. Evaluasi Pelanggan Terhadap Prototipe

Program yang sudah jadi diuji oleh pelanggan, dan bila ada kekurangan pada program bisa ditambahkan.

5. Perbaikan Prototype

Perbaikan program yang sudah jadi, sesuai dengan kebutuhan konsumen. Kemudian dibuat program kembali dan di evaluasi oleh konsumen sampai semua kebutuhan user terpenuhi.

6. Produk Rekayasa

Program yang sudah jadi dan seluruh kebutuhan user sudah terpenuhi

\section{PENELITIAN TERKAIT}

Menurut Agustinus Nilwan dalam bukunya Pemrograman Animasi dan Game Profesional terbitan Elex Media Komputindo, game merupakan permainan komputer yang dibuat dengan teknik dan metode animasi. Jika ingin mendalami pengunaan animasi haruslah memahami pembuatan game. Atau jika ingin membuat game, maka haruslah memahami teknik dan metode animasi, sebab keduanya saling berkaitan (Nilwan, 1998). Menurut Clark C. Abt, Game adalah kegiatan yang melibatkan keputusan 


\section{SYSTEMIC}

Vol. 1, No. 2, Desember 2015, 27-31

pemain, berupaya mencapai tujuan dengan dibatasi oleh konteks tertentu (misalnya, dibatasi oleh peraturan) (C., 1987). Menurut Chris Crawford, seorang computer game designer mengemukakan bahwa game, pada intinya adalah sebuah interaktif, aktivitas yang berpusat pada sebuah pencapaian, ada pelaku aktif (player), ada pelaku pasif (NPC) (Crawford, 2003).

Aplikasi-aplikasi nyata yang paling sukses dari teori permainan banyak diketemukan dalammiliter. Tetapi dengan berkembanganya dunia usaha yang semakin bersaing dan terbatasnya sumber daya serta saling meningkatkan pentingnya aplikasi bisnis teori permainan. Kontrak dan program tawar menawar serta keputusan-keputusan penetapan harga adalah contoh penggunaan teori permainan yang semakin luas. Model-model teori permainan dapat diklasifikasikan dengan sejumlah cara seperti jumlah pemain, jumlah keuntungan dan kerugian dan jumlah strategi yang digunakan dalam permainan. Jika permainan ada 2 pemain, permainan disebut permainan dua pemain. Jika permainan ada $\mathrm{N}$, permainan disebut permainan $\mathrm{N}$ pemain. Jika keuntungan dan kerugian adalah nol disebut permainan jumlah nol (jumlah konstan). Jika keuntungan dan kerugian adalah tidak nol, disebut permainan bukan jumlah nol (Non ZeroZum Game) (Listyorini, 2013).

Alam raya sesungguhnya memiliki warna yang beragam. Warna-warna tersebut dapat kita tangkap karena adanya cahaya. Sebagaimana yang diuraikan yaitu bahwa tanpa cahaya kita tidak akan melihat warna. Cahaya terdiri dari seberkas sinar-sinar yang memiliki panjang gelombang yang berbeda-beda serta memiliki getaran-getaran yang frekuensinya berbeda-beda. Bila gelombang tersebut memasuki mata, maka akan terjadi yang disebut sensasi warna.

Dalam perkembangannya, pemanfaatan game di bidang pendidikan mengalami perkembangan yang signifikan. Semenjak game edukasi berkembang, teori pembelajaran memperoleh inspirasi baru dengan mempertimbangkan game edukasi sebagai salah satu model pembelajaran. Game merupakan kegiatan yang berlangsung dalam batas waktu tertentu dan ruang, dalam urutan permainan, menurut aturan yang berlaku secara bebas, dan di luar lingkup kebutuhan atau kebutuhan material. Permainan merupakan salah satu kegembiraan dan antusiasme, dan sakral atau meriah sesuai dengan kesempatan tersebut (Hakonen, 2005).

Pada saat merencanakan suatu basis data multimedia yang berisi macam macam data dengan format yang berbeda, data di organisasi berdasarkan isi dan penyimpanan fisiknya. Hasil ini dimasksudkan untuk memudahkan pengaksesan pada object/elemen multimedia yang digunakan dalam system (Jasson, 2009).

Pengertian Android adalah sebuah sistem operasi mobile yang open-source dan dikembangkan oleh Google. OS Android digunakan untuk komputer tablet dan smartphone. Namun berdasarkan dari arti kata dan wujudnya, Android merupakan sebuah robot pintar yang dibuat menyerupai manusia. Pengguna android di Indonesia menurut Lembaga riset Sharing Vision belum lama ini mempublikasikan hasil penelitiannya terhadap pengguna Android di Indonesia sepanjang 2013. Pada 2013 sistem operasi Android menguasai sekitar 60\% smartphone beredar di Indonesia. Pertumbuhan pengguna android mencapai lebih dari 1,5 juta per hari di global. Diungkapkannya, aplikasi yang paling sering digunakan pengguna Android di Indonesia adalah Whatsapp(80\%) dan mayoritas $(97 \%)$ responden mengakui bahwa mereka bergabung dengan grup (Listyorini, 2014).

\section{PERANCANGAN GAME EDUKASI PENGENALAN WARNA BERBASIS ANDROID}

Dalam membangun sebuah game edukasi pengenalan warna berbasis android, diperlukan alur perancangan dari game tersebut. Perancangan pada game edukasi ini menggunakan flowchart. Pada gambar 2, menjelaskan alur dari permainan game yang akan dibangun. Pada perancangan game edukasi pengenalan warna ini, terbagi menjadi 3 level yaitu level beginner, level medium dan level expert.

Pada tahap pembangunan game edukasi, dilakukan beberapa tahapan. Yang pertama yaitu desain karakter yang menjadi dasar dari mewarnai. Pemilihan warna dasar yang akan membuat siswa mudah dan menyukai dalam memainkan game ini. Dalam tahapan $70 \%$ ini, penulis membuat rancangan game ini menggunakan emulator android. Tampilan dari prototype game ini ada pada Gambar 3. 


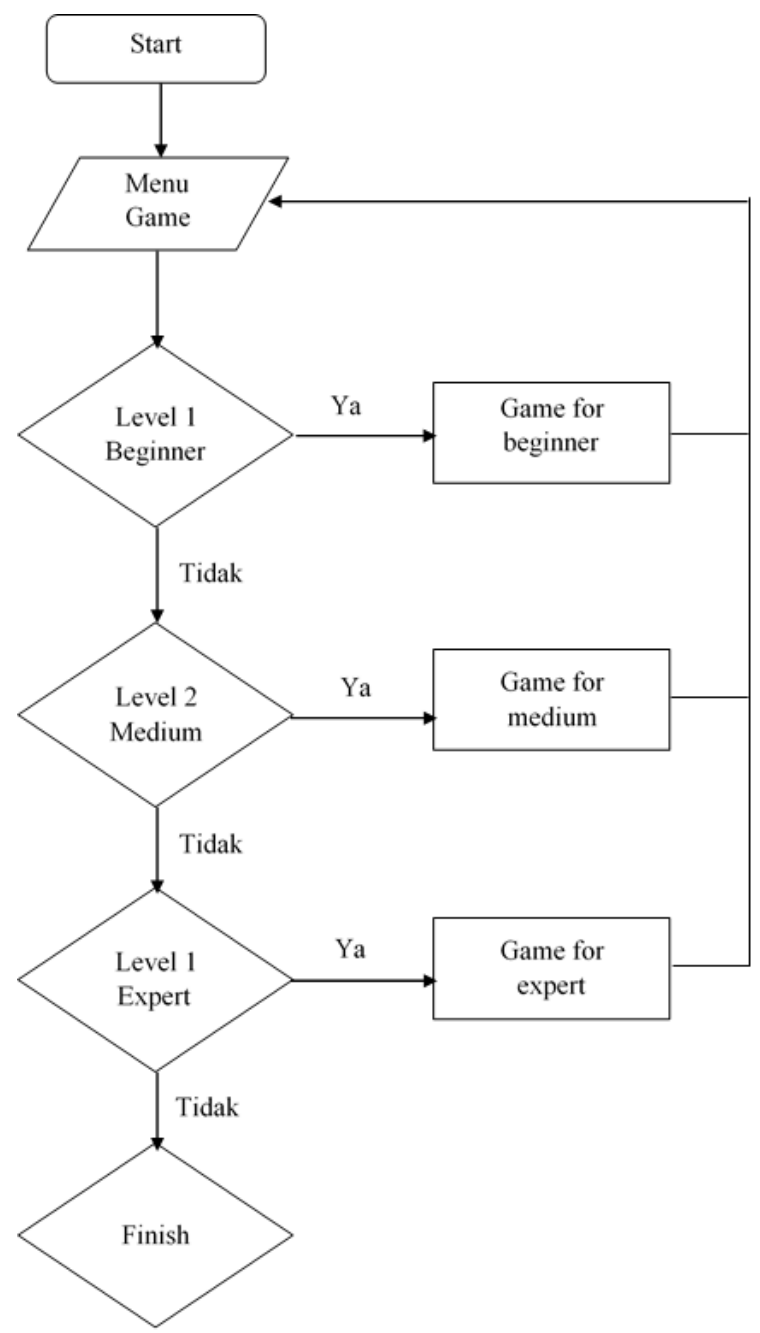

Gambar 2 : flowchart game edukasi pengenalan warna

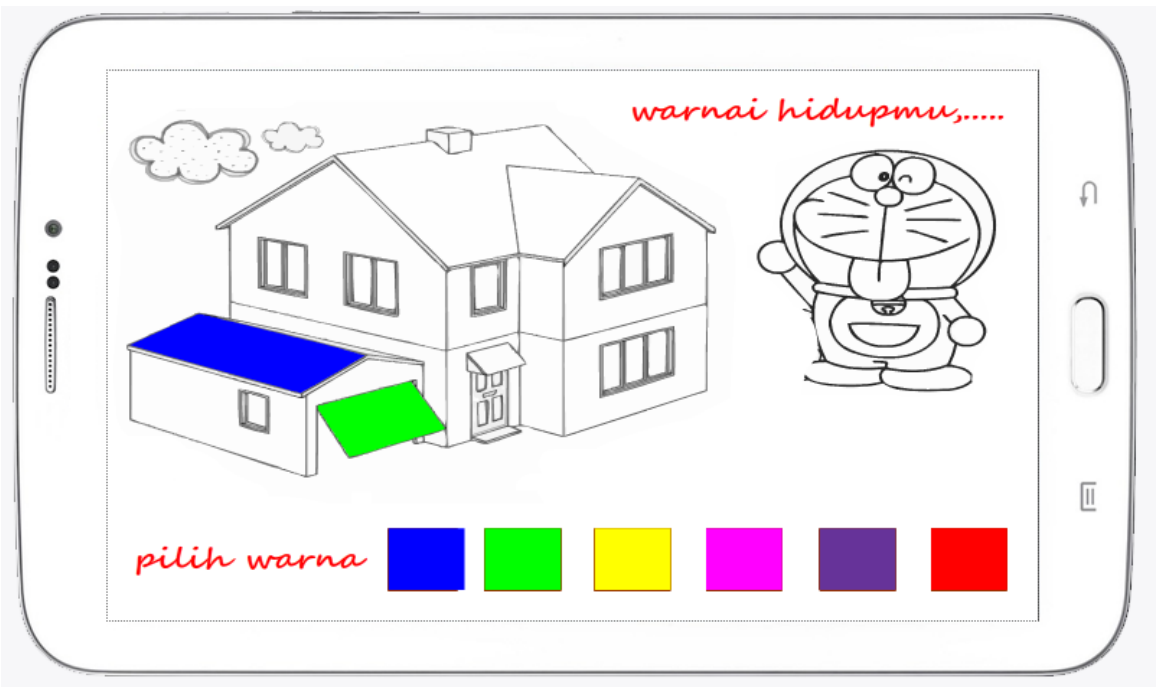

Gambar 3 : Tampilan prototype Game Edukasi Pengenalan Warna 


\section{SYSTEMIC}

Vol. 1, No. 1, Agustus 2015, 20-28

\section{KESIMPULAN}

Pada penelitian ini masih mencapai tahapan $70 \%$, yang hanya meliputi perancangan dan prototype game edukasi ini. Hasil dari penelitian ini adalah menghasilkan sebuah aplikasi Game Edukasi Pengenalan Warna berbasis Android yang dapat diterapkan pada TK Muslimat Khoiriyah Kudus untuk pembelajaran. Untuk tahapan selanjutnya adalah mengaplikasikan game ini pada platform android.

\section{DAFTAR PUSTAKA}

A.S, R. d. S. M., 2010. Modul Pembelajaran Pemrograman Berorientasi Objek dengan Bahasa Pemrograman C++, PHP, dan Java. Bandung: Modula.

Arifianto, T., 2011. Membuat Interface Aplikasi Android Lebih Keren dengan LWUIT. Yogyakarta: Andi Offset.

C., C., 1987. Serious Game. s.1.:s.n.

Crawford, C., 2003. The Art of Computer Game Design. Second Edition ed. United States: Peachpit.

Hakonen, J. S. a. H., 2005. Synthetic Players A Quest for Artificial Intelligence in Computer Games. HUMAN IT, 7(3), pp. 57-77.

Jasson, 2009. Role Playing Game (RPG) Maker (Software Penampung Kreatifitas, Inovasi dan Imajinasi Bagi Game Designer). Yogyakarta: Andi Offset.

Listyorini, T., 2013. Perancangan Game Simulasi Pendaftaran Skripsi Pada Program Studi Teknik Informatika Universitas Muria Kudus. Simetris, 2(1), pp. 56 - 63.

Listyorini, T., 2014. 3d-Catalog Mountain View Resident Berbasis Augmented Reality. Bandung, SAINTIKS. ISSN 978-602-144621-8.

Nazruddin.S., 2012. Android Pemrograman Aplikasi Mobile Smartphone dan Tablet PC Berbasis Android. Bandung: CV. Informatika.

Nilwan, A., 1998. Pemrograman Animasi dan Game Profesional 4. Jakarta: Elex Media Komputindo.

Pressman, R. S., 2007. Rekayasa Perangkat Lunak: pendekatan praktisi (Bukul). Yogyakarta: Andi Offset.

Sugiyono, 2011. Metode Penelitian Pendidikan, Pendekatan Kuantitatif, Kualitatif, dan $R \& D$. Bandung: Alfabeta. 